\title{
Fatty Acid Composition of Flax Sprouts
}

\author{
Satya S. Narina ${ }^{1}$, Anwar A. Hamama ${ }^{1} \&$ Harbans L. Bhardwaj ${ }^{1}$ \\ ${ }^{1}$ Agricultural Research Station, Virginia State University, Petersburg, Virginia, USA \\ Correspondence: Satya S. Narina, Agricultural Research Station, Virginia State University, Petersburg, Virginia, \\ USA. Tel: 1-804-524-1533. E-mail: snarina@vsu.edu
}

Received: December 21, 2012 Accepted: January 30, 2013 Online Published: March 15, 2013

doi:10.5539/jas.v5n4p75

URL: http://dx.doi.org/10.5539/jas.v5n4p75

\begin{abstract}
The oil and fatty acid profile of flax (Linum usitatissimum) sprouts and seed were compared to determine nutrition potential of sprouts. Equal quantities of seed from three flax cultivars (Rahab-94, Pembina and Linott) were sprouted twice in three replications and were analysed for oil and fatty acid contents during summer 2011. Three flax cultivars were observed with high oil content on dry weight basis in sprouts (15.9\%) and seeds (33.99\%). Significant variations $(P<0.0001)$ between seed and sprout values for contents of unsaturated, polyunsaturated (UFA, PUFA) and saturated (SFA) fatty acids $(P=0.0002)$ and non-significant $(P>0.05)$ variation among three cultivars was observed. The percentage of PUFAs in cultivars Pembina and Linott was 68.7 and in Rahab-94 was 67.7. The percentage of linoleic acid (C18:2) was significantly high in sprouts (19.51\%) compared to seed (17.7\%). The percentage of linolenic acid (18:3) was high in seed (52.8\%) compared to sprouts $(48.8 \%)$. The ratio of PUFA/SFA in sprouts was high in Pembina (6.97\%) and Linott (6.82\%) compared to Rahab-94 (6.38\%). The fatty acid profile was similar in all the three cultivars with significant $(P<0.0001)$ reduction $(<1 \%)$ in PUFA/SFA ratio of sprouts compared to seed $(7.4 \%)$. Flax sprouts are equally potential to seed for viable natural resources of essential fatty acids (18:2 and 18:3).
\end{abstract}

Keywords: Linum usitatissimum, oil, MUFA, PUFA, SFA

\section{Introduction}

Flax (Linum usitatissimum), belongs to family Linaceae. Linum species were highly adapted to North America (Sivinski \& Howard, 2011). Dietary fatty acids (Omega 3 and 6) were important for human growth, health and disease (Deckelbaum \& Torrejon, 2012) and a sustainable plant resource is vital for dietary needs. Flax seeds are a good source of essential fatty acids (Omega 3 and 6), lipids, essential amino acids, lignans, and pigments (Oomah, 2001; Westcott \& Muir, 2003; Herchi et al., 2011).

Flax is the potential resource to enrich human diet as ground seed (Bhardwaj et al., 2011) with essential nutrients in sprouts (Narina et al., 2012). The sprouting potential and nutritional values were identified viable in canola (Bhardwaj \& Hamama, 2009), lupin (Hamama \& Bhardwaj, 2004; Bhardwaj \& Hamama, 2012), soybean (Dhakal et al., 2012). The soybean sprouts were high in quantities for genestein and diadzein compared to seed contents, besides appreciable quantities of essential fatty acids and bioactive compounds required for human nutrition (Marton et al., 2010; Orhan et al., 2007).

The amount of triglycerides, free fatty acids (FFA), phospholipids and the fatty acid compositions were determined in flax seed and an increase in FFA and linolenic acid in the phospholipids with germination were observed (Zimmerman \& Klosterman, 1965). A report on fatty acid (FA) composition of flaxseed revealed Omega 3 / Omega 6 ratio of 4:1 was higher than the ratio (1:2) required for humans (www.curezone.com).

Cultivar variations for sprout quality were significant for unsaturated fatty acid and oil contents of soybean and Canola (Dhakal et al., 2012; Bhardwaj \& Hamama, 2009). Significantly high ratio of 18:2/18:3 was observed in sprouts of Virginia cultivar of Canola (Bhardwaj \& Hamama, 2009). Seeds of sesame were high for contents of oleic and linoleic acids (80-85\%) compared to palmitic and stearic acid (Biglari et al., 2012).

Flax sprouts were reported with $22.3 \%$ protein, $17.0 \%$ crude fiber and $8.1 \%$ total sugars on dry weight basis (Narina et al., 2012). There were no reports to date on fatty acid composition of flax sprouts.Therefore, our objective is to analyze the oil content and fatty acid profiles for both flaxseed and sprouts of three cultivars and compare those values with other related crop seed sprouts like Canola and soybean. 


\section{Materials and Methods}

Three flax cultivars (Rahab-94, Pembina and Linott) from germplasm collections of the New Crops Program were grown at the Randolph farm at VSU-ARS, Petersburg, VA. The matured seed from these three cultivars was used for raising sprouts. The sprout experiment was replicated thrice with three cultivars and conducted twice during 2011. An ample quantity of sprout was achieved for analysis from six biological sample replicates of six grams in each variety. The standard laboratory procedures (Narina et al., 2012) were used to raise sprouts from the seeds of three flax cultivars. The sprouts were harvested on the fourth day and were immediately freeze dried and stored in -80 degrees for further biochemical analysis.

The fine ground powder of freeze dried sprouts and seeds of the three cultivars were used to determine oil contents (gram/100g dry weight basis) and fatty acid composition (wt \% of total fatty acids) using previously published protocols (Bhardwaj \& Hamama, 2009). The chemicals and reagents used for analysis were HPLC grade and were obtained from Sigma-Aldrich Corporation (St. Louis, MO, USA) and Fisher Scientific (Pittsburgh, PA).

\subsection{Statistical Analysis}

Analysis of variance procedures (PROC GLM) in version 9.3 of SAS (SAS, 2012) were used to analyze the data generated. The sprout nutrient data was compared with those of seed and other related new crop sprouts (Table 2) to determine the potential of flax sprouts for nutritional values.

\section{Results and Discussion}

The average fresh sprout yield was $28.27 \mathrm{~g}$ from six grams seed. There were no significant differences observed among the three cultivars for major fatty acid (FA) and oil contents analyzed (Table 1). The oil content of sprouts $(15.9 \%)$ was significantly low to that of seed $(33.9 \%)$. The seeds are with very low water content compared to sprouts with high water content asthe process of germination will change the triglycerides composition to hydrolysis free fatty acids like linoleic acid (Marton et al., 2010). Most of the oil lost from seed was used as energy necessary for the growth of sprout (Orhan et al., 2007; Bhardwaj \& Hamama, 2009).

The major FA composition for three cultivars was expressed as percentage of total fatty acid (Table 1 ). These FAs are classified into three main categories saturated (SFA-16:0, 18:0, 20:0 and 22:0), monounsaturated (MUFA-18:1, oleic and 20:1, eicasanoic) and polyunsaturated fatty acids (PUFA-18:2, linoleic and 18:3, linolenic acid).

There were non significant differences among three cultivars for saturated or unsaturated fatty acid contents. We observed non-significant variations $(P=0.07)$ for polyunsaturated fatty acids $(18: 2$ and $18: 3)$ and monounsaturated fatty acids (18:1 and 20:1) for seed and sprout values. The variety Pembina was with high contents of 18:3 (49.6\%) and Rahab-94 was with 18:2 (20\%), were significantly different from Linott at $7 \%$ level of significance. The monounsaturated fatty acids were relatively similar in seed and sprout $(20 \%$ oleic and $0.22 \%$ eicosanoic acid) values of all the cultivars. These results indicate that the sprout could be as viable as ground seed to provide equal quantities of fatty acids and could impact human health by protecting against cardiovascular diseases (Bhardwaj et al., 2012) or osteoporosis in humans (Orhan et al., 2007).

The saturated and unsaturated fatty acid compositions of sprouts $(10.2 \%$ and $89.1 \%)$ were significantly different $(0.0002<P<0.0001)$ from those of seed $(9.5 \%$ and $90.4 \%)$. The present investigation revealed highest levels of UFAs in sprouts $(89.1 \%)$ due to high levels of antioxidants that help to protect humans from oxidative stress (Lampi et al., 2002; Orhan et al., 2007). Similar findings were reportedin sprouts of soybean (Orhan et al., 2007) and flax (Narina et al., 2012) with significant amount and number of anti-oxidants.

Significantly high levels of total PUFAs (68.31\% on dry weight basis) were observed in sprouts and were relatively similar in all the cultivars. Approximately $100 \mathrm{~g}$ of fresh sprouts were yielding $23.41 \mathrm{~g}$ of dry sprouts. Therefore, an amount $427.21 \mathrm{~g}$ of fresh sprouts required to get $68.31 \mathrm{mg}$ of PUFA or $15.99 \mathrm{mg}$ of PUFA/100g of sprout on an average.

The percentage of total PUFAs in seed were high (70.61\%) to those of sprouts, while the percentage of linoleic acid (C18:2) was high in sprouts (19.51\%) compared to seeds (17.7\%). The linolenic acid (18:3) content was 4 percent more (52.85\%) in seed compared to sprouts (48.8\%). Flax seed was a rich source of linolenic acid (LA), containing over $50 \%$ of its fatty acids as $\alpha$-linolenic acid (LNA), Omega-3 fatty acid (www.curezone.com). The ratio of PUFA/SFA in sprouts was high in Pembina (6.97\%) and Linott (6.82\%) compared to Rahab-94 (6.38\%), but were relatively similar in values to those of seed (7.4\%). Thus, the flax sprouts are the nutritionally valuable sourceproviding high contents of linoleic (18:2) and linolenic (18:3) acid and were in line with previous findings in canola and soybean sprouts (Bhardwaj \& Hamama, 2009; Orhan et al., 2007). 
Table 1. Major fatty acid composition of seeds and sprouts of three flax cultivars

\begin{tabular}{|c|c|c|c|c|c|c|c|c|}
\hline \multirow{2}{*}{$\begin{array}{l}\text { Fatty acid and } \\
\text { Oil } \\
\text { Composition }\end{array}$} & \multicolumn{4}{|c|}{ Sprouts } & \multicolumn{4}{|c|}{ Ground seed powder } \\
\hline & Rahab 94 & Linott & Pembina & $\begin{array}{l}\text { Average } \\
\text { (Sprout) }\end{array}$ & Rahab 94 & Linott & Pembina & $\begin{array}{c}\text { Average } \\
\text { (Seed) }\end{array}$ \\
\hline Oil \% & $14.9 \pm 2.81 \mathrm{x}$ & $16.86 \pm 3.79 \mathrm{x}$ & $15.9 \pm 1.46 \mathrm{x}$ & 15.9 & $37.27 \pm 0.51 \mathrm{x}$ & $33.38 \pm 0.04 y$ & $31.32 \pm 0.64 \mathrm{y}$ & 33.99 \\
\hline \multicolumn{9}{|l|}{ Saturated FA } \\
\hline $\mathrm{C} 16: 0$ & $5.22 \pm 0.21 \mathrm{x}$ & $5.22 \pm 0.47 \mathrm{x}$ & $5.00 \pm 0.20 \mathrm{x}$ & 5.14 & $5.26 \pm 0.14 \mathrm{x}$ & $5.27 \pm 0.01 \mathrm{x}$ & $5.3 \pm 0.09 \mathrm{x}$ & 5.28 \\
\hline C18:0 & $4.66 \pm 0.31 \mathrm{x}$ & $4.13 \pm 0.44 \mathrm{x}$ & $4.27 \pm 0.53 \mathrm{x}$ & 4.35 & $3.92 \pm 0.41 \mathrm{x}$ & $3.91 \pm 0.01 \mathrm{x}$ & $3.98 \pm 0.37 \mathrm{x}$ & 3.94 \\
\hline $\mathrm{C} 20: 0$ & $0.31 \pm 0.02 \mathrm{x}$ & $0.29 \pm 0.05 x y$ & $0.25 \pm 0.01 \mathrm{y}$ & 0.28 & $0.15 \pm 0.02 x$ & $0.15 \pm 0.0 \mathrm{x}$ & $0.16 \pm 0.01 \mathrm{x}$ & 0.15 \\
\hline $\mathrm{C} 22: 0$ & $0.44 \pm 0.04 \mathrm{x}$ & $0.42 \pm 0.09 x$ & $0.33 \pm 0.02 \mathrm{y}$ & 0.39 & $0.14 \pm 0.02 x$ & $0.13 \pm 0.00 \mathrm{x}$ & $0.14 \pm 0.01 \mathrm{x}$ & 0.14 \\
\hline \multicolumn{9}{|l|}{ Unsaturated } \\
\hline \multicolumn{9}{|l|}{ FA } \\
\hline C18:1 & $20.6 \pm 0.90 x$ & $20.33 \pm 0.33 x$ & $20.75 \pm 0.18 x$ & 20.56 & $19.61 \pm 0.67 \mathrm{x}$ & $19.51 \pm 0.01 \mathrm{x}$ & $19.60 \pm 0.67 \mathrm{x}$ & 19.57 \\
\hline $\mathrm{C} 18: 2$ & $20.0 \pm 0.51 x$ & $19.49 \pm 0.51 x y$ & $19.05 \pm 0.66 \mathrm{y}$ & 19.51 & $17.75 \pm 0.37 \mathrm{x}$ & $17.73 \pm 0.01 \mathrm{x}$ & $17.81 \pm 0.18 \mathrm{x}$ & 17.76 \\
\hline $\mathrm{C} 18: 3$ & $47.8 \pm 0.96 \mathrm{x}$ & $49.1 \pm 1.44 x y$ & $49.6 \pm 1.06 y$ & 48.8 & $52.88 \pm 1.03 y$ & $52.98 \pm 0.01 x y$ & $52.7 \pm 1.13 x$ & 52.85 \\
\hline $\mathrm{C} 20: 1$ & $0.23 \pm 0.01 \mathrm{x}$ & $0.23 \pm 0.01 \mathrm{x}$ & $0.23 \pm 0.01 \mathrm{x}$ & 0.23 & $0.22 \pm 0.01 \mathrm{x}$ & $0.22 \pm 0.01 \mathrm{x}$ & $0.22 \pm 0.01 \mathrm{x}$ & 00.22 \\
\hline$\sum \mathrm{SFA}$ & $10.63 \pm 0.54 \mathrm{x}$ & $10.06 \pm 1.05 x$ & $9.85 \pm 0.33 y$ & 10.16 & $9.47 \pm 0.40 \mathrm{x}$ & $9.46 \pm 0.01 \mathrm{x}$ & $9.58 \pm 0.30 \mathrm{y}$ & 9.50 \\
\hline$\sum$ UFA & $88.63 \pm 0.52 x$ & $89.15 \pm 1.16 y$ & $89.63 \pm 0.33 y$ & 89.1 & $90.46 \pm 0.39 \mathrm{x}$ & $90.44 \pm 0.05 x$ & $90.33 \pm 0.31 \mathrm{x}$ & 90.41 \\
\hline$\sum$ MUFA & $20.8 \pm 0.91 x$ & $20.6 \pm 0.32 x$ & $20.98 \pm 0.18 \mathrm{y}$ & 20.8 & $19.82 \pm 0.67$ & $19.73 \pm 0.01$ & $19.82 \pm 0.63$ & 19.79 \\
\hline$\sum$ PUFA & $67.8 \pm 1.41 x$ & $68.59 \pm 0.96 x y$ & $68.65 \pm 0.46 y$ & 68.31 & $70.63 \pm 0.84 x y$ & $70.71 \pm 0.01 \mathrm{x}$ & $70.51 \pm 0.95 y$ & 70.61 \\
\hline $\begin{array}{c}\sum \text { PUFA / } \\
\sum \text { SFA }\end{array}$ & $6.38 \pm 0.46 \mathrm{x}$ & $6.82 \pm 0.8 \mathrm{y}$ & $6.97 \pm 0.28 \mathrm{y}$ & 6.72 & $7.46 \pm 0.38 \mathrm{x}$ & $7.47 \pm 0.01 \mathrm{x}$ & $7.36 \pm 0.33 y$ & 07.43 \\
\hline
\end{tabular}

Thevalues of oil and fatty acid compositions is the mean of three measurements as weight percent (wt \%) total FAs from three replications and two experiments; Means with same letter $(\mathrm{x} / \mathrm{y})$ are not significantly different $(0.46<p>0.07)$.

FA- Fatty Acid; $\sum$ SFA - sum of saturated fatty acids $(16: 0+18: 0+20: 0+22: 0)$;

$\sum$ UFA -sum of unsaturated fatty acids $(18: 1+18: 2+18: 3+20: 1)$;

$\sum$ MUFA - sum of monounsaturated fatty acids $(18: 1+20: 1)$;

$\sum$ PUFA - sum of polyunsaturated fatty acids (18:2+18:3).

Comparision of fatty acid and oil traits of flax sprouts with those of canola and soybean sprouts (Table 2) revelaed that Canola sprouts were high in contents for all the components analysed except for 18:3 (48.8\%) and 18:2 $(19.51 \%)$, the proportions of fatty acids analysed on percent weight basis, showing the siginificance and impact of flax sprouts in nutrtion as dietary source. The reason for high levels of C18:3 in flax sprouts (48.8\%) might be due to highest accumulation of $\gamma$ - tocopherol at seed maturity (Herchi et al., 2011; Kamal-Eldin \& Appelqvist, 1996) compared to those accumulated in canola seed. 
Table 2. Comparison of fatty acid and oil traits of flax seed sprouts with those of Canola and soybean

\begin{tabular}{|c|c|c|c|}
\hline Oil / FA composition* & Flax & Canola & Soybean \\
\hline Oil\% & 15.9 & 27.33 & 0.03 \\
\hline \multicolumn{4}{|l|}{ Saturated FA } \\
\hline C16:0 & 5.14 & 5.38 & $31.13 \pm 0.90$ \\
\hline C18:0 & 4.35 & 1.21 & $1.80 \pm 0.03$ \\
\hline C20:0 & 0.28 & 0.53 & - \\
\hline $\mathrm{C} 22: 0$ & 0.39 & 0.27 & $2.27 \pm 0.36$ \\
\hline \multicolumn{4}{|l|}{ Unsaturated FA } \\
\hline C18:1 & 20.56 & 45.71 & $5.79 \pm 0.52$ \\
\hline C18:2 & 19.51 & 18.35 & $15.27 \pm 1.09$ \\
\hline C18:3 & 48.8 & 8.82 & $23.57 \pm 1.25$ \\
\hline C20:1 & 0.23 & 7.44 & - \\
\hline$\sum \mathrm{SFA}$ & 10.16 & 7.54 & 35.2 \\
\hline$\sum$ UFA & 89.1 & 92.46 & 44.63 \\
\hline$\sum \mathrm{UFA} / \sum \mathrm{SFA}$ & 8.77 & 12.26 & 1.27 \\
\hline$\sum$ PUFA & 68.31 & 27.17 & 38.62 \\
\hline$\sum \mathrm{PUFA} / \sum \mathrm{SFA}$ & 6.72 & 3.60 & 1.10 \\
\hline $18: 3 / 18: 2$ & 2.50 & 2.08 & 1.54 \\
\hline
\end{tabular}

*The Oil and FA content were expressed in $\mathrm{g} / 100 \mathrm{~g}$ dry weight basis. The sprout data for canola and soybean was retrieved from peer reviewed publication of Bhardwaj and Hamama (2009) and Orah et al. (2007) for fatty acid profile comparisons.

\section{Conclusion}

Significantly low oil content in sprouts compared to seed and relatively similar fatty acid profiles for seed and sprout with equally potential values for essential fatty acid compositions (Omega 2 and 3 ) were observed in the study.The possible potential use of flax sprouts as supplementary dietary source to replace the different forms of flaxseed. Evaluations for seed sprouts to study the influence of seed maturity on fatty acid contents, tocopherols, sterols and other bioactive compounds will give better understanding of nutritional quality of sprouts. Analysis of sprouts from more cultivars including golden yellow seed will aid for future crop improvement for nutrition quality.

\section{Acknowledgement}

This project was supported by USDA-NIFA-Capacity Building Grants program. I like to acknowledge Dr. Corley and Dr. Xu for reviewing the manuscript before submission. This is the contribution of Virginia State University, Agricultural Research Station, Journal Article Series No.300.

\section{References}

Bhardwaj, H. L., \& Hamama, A. A. (2007). Yield and nutritional quality of canola sprouts. Hort Science, 42(7), 1656-1658.

Bhardwaj, H. L., \& Hamama, A. A. (2009a). Cultivar and growing location effects on oil and fatty acid composition of canola sprouts. Hort Science, 44(6), 1628-1631.

Bhardwaj, H. L., \& Hamama, A. A. (2009b). Effect of cultivar and growing location on the mineral composition of canola sprouts. Hort Science, 44(2), 508-511.

Bhardwaj, H. L., \& Hamama, A. A. (2012). Yield \& nutritional quality traits of White Lupin sprouts. Journal of Agricultural Science, 4(1), 58-61.

Bhardwaj, H. L., Hamama, A. A., Narina, S. S., \& Parry, J. (2012). Consumption of ground wholeseed flax and human blood traits. Journal of Agricultural Science, 4(8), 106-111. 
Biglari, M., Moghaddam, G., Sadeghi, N., Oveisi, M. R., Jannat, B., Kaboli, Z., \& Hajimahmood, M. (2012). Profiling of major fatty acids in different raw and roasted sesame seeds cultivars. African Journal of Biotechnology, 11(4), 6619-6623. http://dx.doi.org/10.5897/AJB11.1966

Deckelbaum, R. J., \& Torrejon, C. (2012). The Omega-3 fattya acid nutritional landscape: Health Benefits and sources. The journal of nutrition. http://dx.doi.org/10.3945/jn.111.148080

Dhakal, K. H., Jeong, Y. S., Lee, J. D., Baek, I. Y., Ha, T. J., \& Hwang, Y. H. (2012). Fatty acid composition in each structural part of soybean seed and sprout. Journal of Crop Science and Biotechnology, 12(2), 97-101. http://dx.doi.org/10.1007/s12892-009-0092-x

Hamama, A. A., \& Bhardwaj, H. L. (2004). Phytosterols, triterpene alcohols and phospholipids in seed oil from white lupin. Journal of the American Oil Chemists' Society, 81, 1039-1044.

Herchi, W., Sakouhi, F., Boukchina, S., Kallel, H., \& Claude, P. (2011). Changes in Fatty acids, tocochromanols, carotenoids and chlorophylls content during flaxseed development. Journal of the American Oil Chemists' Society, 88, 1011-1017. http://dx.doi.org/10.1007/s11746-010-1750-3

Kamal-Eldin, A., \& Appelqvist, L. A. (1996). The chemistry and antioxidant properties of tocopherols and tocotrienols. Lipids, 31, 671-701.

Lampi, A. M., Kamal-Eldin, A., \& Piironen, V. (2002). Tocopherols and tocotrienols from oil and cereal grains. In J. Shi, G. Mazza, \& M. L. Maguer (Eds.), Functional foods. Biochemical and processing aspects, Vol 2. Boca Rato: CRC Press,

Marton, M., Manoki, Zs., Csapo-Kiss, Zs., \& Csapo, J. (2010). The role of sprouts in human nutrition, A review. Acat Univ. Sapientiae, Alimentaria, 3, 81-117.

Narina, S. S., Hamama, H. A., \& Bhardwaj, H. L. (2012). Nutritional and Mineral composition of flax sprouts. Journal of Agricultural Sciences, 4(11), 2012.

Oomah, B. D. (2001). Flax seed as a functional food source. J. Sci. Food Agr., 81, 889-894.

Orhan, I., Ozcelik, B., Kartal, M., Sinem, A., Bilge, S., \& Ozguven, M. (2007). Qunatification of Daidzen, Genistein and fatty acids in soybeans and soy sprouts and some bioactivity studies. Acta Biologica Cracoviensia Series Botanica, 49(2), 61-68.

Peer, D. J., \& Leeson, S. (1985). Nutrient content of hydroponically sprouted barley. Anim. Feed Sci. Technol., 13, 191-202.

SAS Version 9.3. (2012). SAS system for windows. SAS Institute, Inc, Cary, NC

Sivinski, R. C., \& Howard, M. O. (2011). A new species of Linum from the northern Chihuahuan Desert. Phytoneuron, 33, 1-7.

Westcott, N. D., \& Muir, A. D. (2003). Flax seed lignans in disease prevention and health promotion. Phytochemi Rev., 2, 401-417.

Zimmerman, D. C., \& Klosterman, H. J. (1965). Lipid metabolism in germinating flax seed. Journal of the American Oil Chemists' Society, 42(1), 58-62. http://dx.doi.org/10.1007/BF02558258 